\title{
Diagnosis of the Operational Gear Wheel Wear
}

\author{
Rafał GOŁĘBSKI, Arkadiusz SZAREK
}

\begin{abstract}
The article presents an analysis in the field of gear wheel testing method application. The results of tests of gear wheel teeth taken from a damaged gear rim are reposted. Tests were carried out on specimens to establish the causes of gear wheel tooth cracking. Macroscopic examination was made, which confirmed the occurrence of top layer spalling. An analysis to examine the damage to the surfaces of mating gear wheels is described. A destructive testing method was employed. The results of hardness and microhardness tests and metallographic analysis are presented.
\end{abstract}

Keywords: destructive testing; hardness; microhardness; spur gear

\section{INTRODUCTION}

It can be claimed with reasonable certainty that gear wheels continue to be among the power transmission assemblies that are the most widely used in machinery and equipment. In the process of transmission gear manufacture it is essential to optimally select the production method. Gear wheels are machined mainly by the hobbing method using modular hobs, which is the most efficient method, but also with pull broaches, Fellows cutters or dedicated milling cutters [1]. Quite often, modification to the profile of a gear results in an improvement in its operating properties $[2,3,4,5]$. In the finishing machining process, grinding is common [6]. The majority of machine failures are caused by damage to the top layer of the mating parts [7]. Friction processes in solid bodies occur in the top layer. Therefore, very often, an initiation of decohesion processes can be observed after machining $[8,9]$. So, it becomes necessary to spare no efforts to prepare gear wheel manufacture technologies that will prevent the adverse effects of phenomena occurring during machining, which negatively affect the surface condition after machining $[10,11,12]$.

The operating endurance of a gear wheel, being considered as the sum of its bulk strength and surface strength, is closely related to the properties of its top layer. For this reason, varying technological and operating top layer production methods are used, which rely on the new methods of machining, surfacing, plastic working, etc., and new operating gear grind-in methods [7].

Gear operation conditions determine the requirements for the properties of the gear wheel top layer. If we consider the actual metal structure as a set of breaks in the continuity of the macro- and microscopic structure, composed of gaps, pores and structure irregularities of a laminar or mosaic nature or caused by foreign matter inclusions, we will be able to conclude that the role of the operating top surface layer of gear wheels during their mating is even more clearly pronounced.

When analyzing factors influencing the gear wear, it can be noticed that they are multiple.

Among the most effective methods of detecting gear wheel defects occurred due to irregularities in the gear wheel manufacture process are destructive tests $[13,14]$. It is only thanks to them that we are able to make a detailed analysis to determine the chemical composition of the material and to perform metallographic analysis that is very important for verifying the correctness of the heat treatment process applied.

\section{TOOTH FAILURE TYPES}

On account of the mode of operation of the gear, that is, e.g., its continuous operation, the failures occurring in gears can be classified into those that stop the operation of the entire drive unit, and those that do not stop the operation of the gear, but only impair its operating properties. Irrespective of the severity of a gear wheel (tooth) failure, the repair of the gear wheel is often impossible; in that case, the whole damaged gear wheel or, very often, several mating gear wheels need to be replaced. The most frequent causes of gear wheel failure include tooth stresses, surface pressures and occurring friction [7, $15,16]$. Due to the effect of the above-mentioned factors, tooth failures may occur, which include primarily abrasive wear, spalling, gear seizure and pitting.

The aforementioned failures may also occur due to other factors resulting from errors in the preparation of the technological process, e.g. a faulty heat treatment, such as overheating during treatment. Very often, errors made during assembling the gear have a tremendous effect on its behaviour in operation. An assembling error or an incorrect setting of an axle distance very often may change the location of the tooth contact field and, as a consequence, lead to a tooth edge break-off.

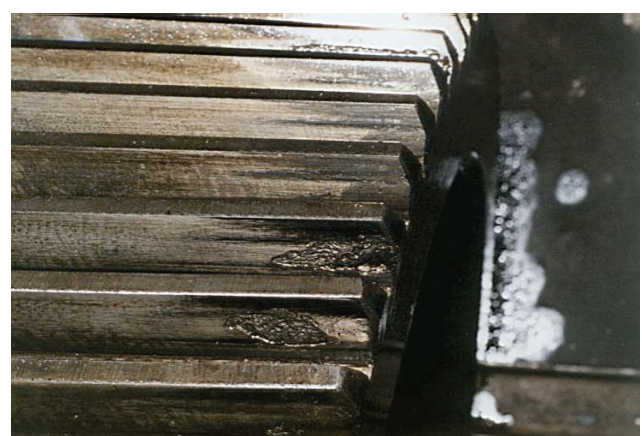

Figure 1 Tooth flank damage occurred due to pitting.

Tooth flanks most often fail in the case of gear wheels made of steel. The most common type of operation wear is pitting. This is a very dangerous phenomenon that may result in a break-off of the whole tooth. Pitting arises due 
to the friction of tooth flanks in the presence of a lubricant, whose boundary layers are characterized by very high cohesion $[6,7]$. Toothed gears are subject to cyclic loading that causes very high unit surface pressures [5]; because of this, the failures have the character of typical material fatigue failures. Top layer spalling arises on tooth flanks due to the occurrence of cyclic loads. Very often, this phenomenon is preceded by progressive pitting - Fig. 1 .

Most often, a tooth is broken in the location where a stress concentration has occurred during operation. This is frequently associated with a notch zone at the tooth base. Machining or hardening scratches, or fatigue spalling pitting, which break the continuity of the tooth flank structure, may also cause fatigue fractures [7].

The photo in Fig. 2 shows a case of tooth wear by braking off. A tooth break is a consequence of the occurrence of pitting at an advanced degree, along with tooth top layer spalling.

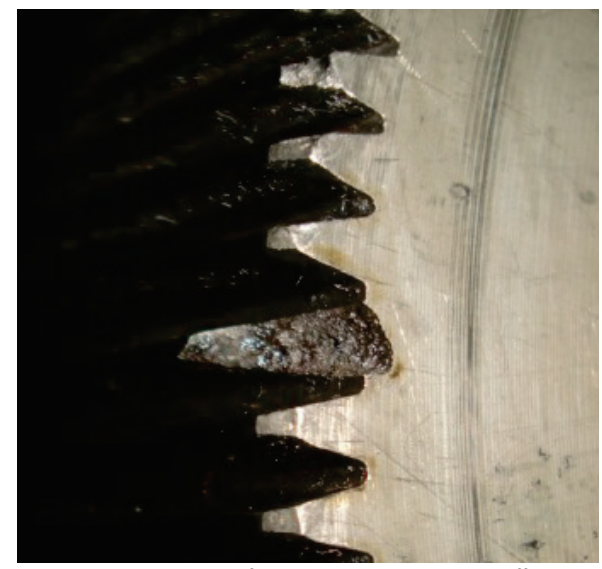

Figure 2 Tooth flank damage by braking off

\section{GEAR WHEEL FAILURE ANALYSIS}

Spur gears with visible failures in the form of mating surfaces spalling - Fig. 1, and tooth break-offs - Fig. 2, were subjected to investigation. The gears were put to prolonged operation. The operating conditions did not show that the gears might be operating under a load higher than standard. The machine included six pairs of gears that performed identical transmission jobs. Some top layer spalling, at a varying stage of advancement, could be observed on all the gears. Only two gears failed by breaking off. The material grade, of which the gears were made, was not known. On selected gears, the following examinations and tests were carried out:

- the chemical examination of the material used for the manufacture of the gear wheels,

- the microhardness and hardness tests of the gear tooth mating surface, and

macroscopic and microscopic metallographic examination.

The examinations and tests were carried out to establish the causes of the gear wheel failures, and to determine the structure of the metals and alloys, the thickness and structure of the top layers, and the topography of the mating surfaces.

\subsection{Identification of Gear Wheel Material}

The identification of the metals by determining the chemical composition of the material is presently the standard in the inspection process in the case of any doubts as to whether the correct material grade was used in the production process. An X-ray fluorescence spectrometer was used for the measurement. Three specimens taken from 3 different gears were subjected to analysis. Tab. 1 shows the averaged results of measurements for the presence of elements, along with their percentage contents.

Table 1 Chemical composition of the examined tooth specimens
\begin{tabular}{|c|c|c|c|c|c|c|c|}
\hline $\mathrm{C}$ & $\mathrm{Mn}$ & $\mathrm{Si}$ & $\mathrm{P}$ & $\mathrm{S}$ & $\mathrm{Cr}$ & $\mathrm{Ni}$ & $\mathrm{Mo}$ \\
\hline 0.42 & 0.51 & 0.23 & 0.02 & 0.007 & 0.98 & 0.17 & 0.19 \\
\hline
\end{tabular}

Based on the obtained percentage contents of alloying elements, it was found that the material grade of which the gear wheels were made was steel 42CrMo4 [17]. Not knowing the designer's specifications and having no detailed technological documentation available, it was supposed that the grade of material used for the gear wheel manufacture had been correct and might have been subjected to hardening. This is a material that is commonly used for machine parts of very high strength and ductility, and especially for elements exposed to variable loads. Steel $42 \mathrm{CrMo} 4$ is amenable to toughening and hardening; as hardened, its hardness is around 60HRC. The steel is very well machinable.

\subsection{Hardness and Microhardness Tests}

The hardness test was performed using a portable device, Krautkramer MIC 10. The small and narrow probe of this device enabled the test to be done in hardly accessible locations, such as, in the case under discussion, those on the tooth flank. The size of the Vickers indenter is electronically measured and indicated directly on the LCD display as a hardness value, without having to take measurements under a microscope. All gear wheels with defects, as well as faultless ones, were subjected to analysis. Hardness tests done on gear flanks preliminarily qualified 4 teeth for further analysis. On the flank of 3 teeth, the hardness of the gear wheels ranged around 740 $\mathrm{HV}$. This result is quite correct for the material class under investigation. In the case of a gear wheel with an obvious defect in the form of pitting, the hardness in the vicinity of the defect was $420 \mathrm{HV}$. The gear wheels qualified for further testing were subjected to machining involving the turning of a rim and cutting out of indicated teeth. The machining was conducted with intensive cooling to avoid the influence of heat on the test material.

At the next stage, a hardness test was performed in the section normal in two directions: from the tooth point and from the tooth flank. Fig. 3 shows the results of the measurements of hardness distribution in the direction from the tooth point. The hardness of specimen no. 1 significantly deviates from that of the other specimens.

A similar situation is for the hardness test in the direction from the tooth flank - Fig. 4.

In the case under consideration, for gear wheels subjected to induction hardening, the depth of the nominal hardened layer should not be less than $1.8 \mathrm{~mm}$, while 
retaining a hardness of 600-650 HV [18]. All tooth specimens do not show the correct hardness distribution. At the subsequent stage, the specimens of gear wheels nos. 1 and 4 were subjected to microhardness distribution measurement.

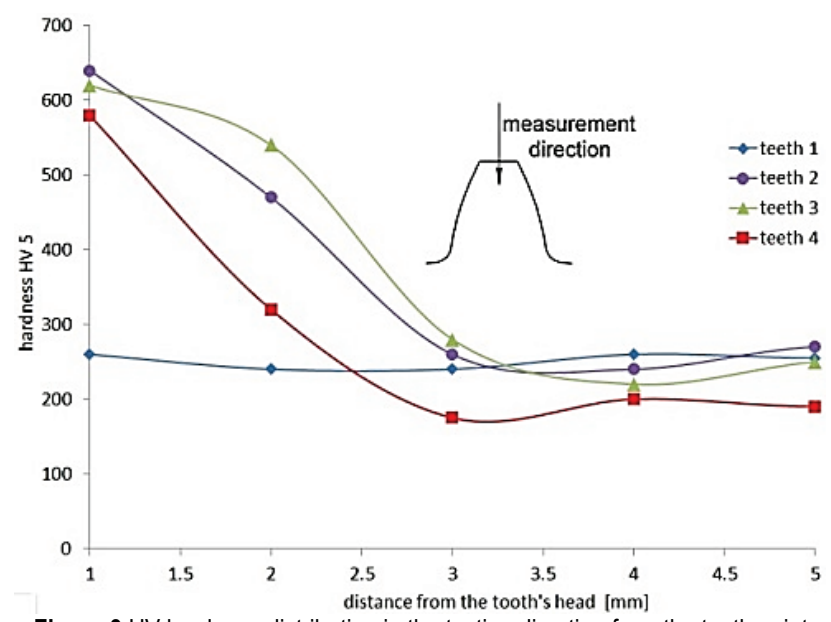

Figure $3 \mathrm{HV}$ hardness distribution in the testing direction from the tooth point

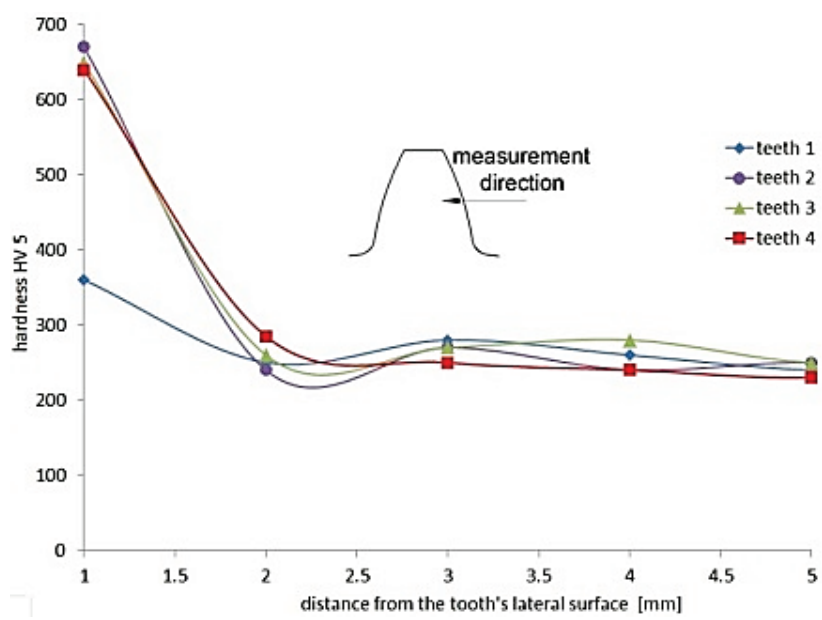

Figure $4 \mathrm{HV}$ hardness distribution in the testing direction from the tooth flank

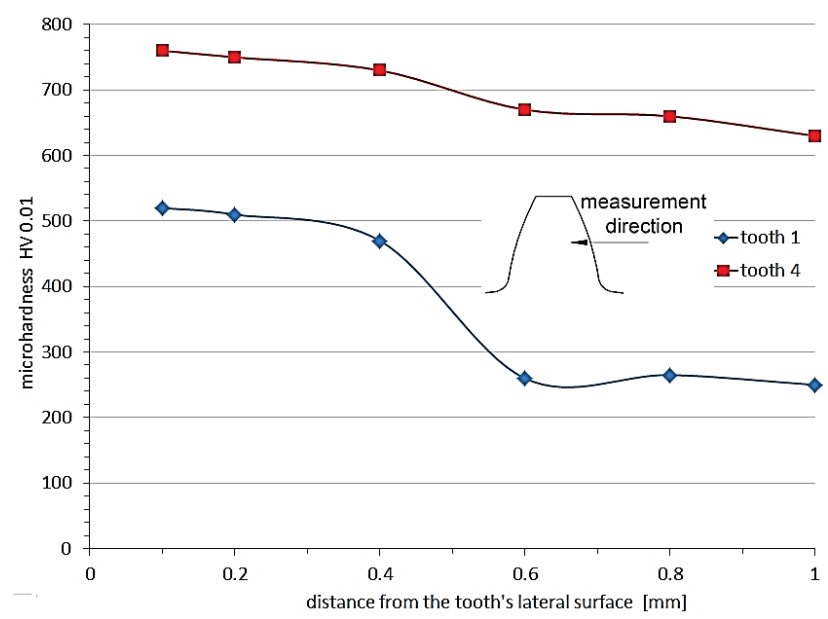

Figure $5 \mathrm{HV}$ microhardness distribution in the testing direction from the tooth flank

Fig. 5 illustrates the microhardness test of tooth no. 1 damaged due to pitting - Fig. 1, and tooth no. 4 with no visible defects. When analyzing the microhardness distribution, it can be noticed that the hardness drop boundary coincides with the crack distance from the tooth flank, which is approx. $0.6 \mathrm{~mm}$. It can be seen that the spalling thickness is approximately equal to the thickness of the hardened layer. The examination allowed us to infer that there was a non-uniform distribution of hardening depth for the whole gear wheel. At that stage of investigation, however, it was not possible to determine explicitly whether this had happened due to incorrect parameters in the hardening process or as a result of some technological errors made in finishing machining by grinding.

\subsection{Macroscopic Metallographic Examinations}

Fig. 6 represents teeth nos. 1 and 4 as Nital etched. At 6-times magnification, it was possible to observe nonuniform distributions of the hardened layer zone. In the case of tooth no. 1 (with visible defects), one can notice that on the tooth flanks, and especially within the useful region of mating surfaces, the hardening zone practically does not exist. For tooth no. 4 (with no visible defects), the distribution of hardening depth is also non-uniform. It was established conclusively that, as a result of the gear wheel grinding process, almost all hardened zone had been removed. This is a consequence of a wrongly performed induction hardening process, which had left an insufficient allowance for finishing gear wheel machining.

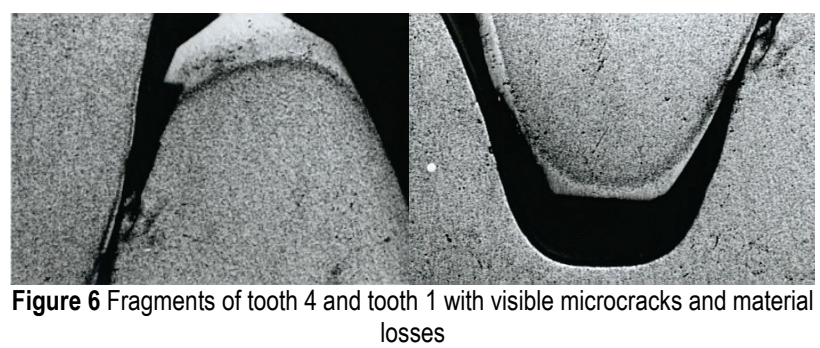

\subsection{Microscopic Metallographic Examinations}

Photograph 7 shows a microstructure at the edge of tooth 1 . This is a diphase structure of the bainitic type, which is characterized by the acicular structure of the bainitic ferrite matrix, and slender agglomerations of a second phase between the ferrite spines.

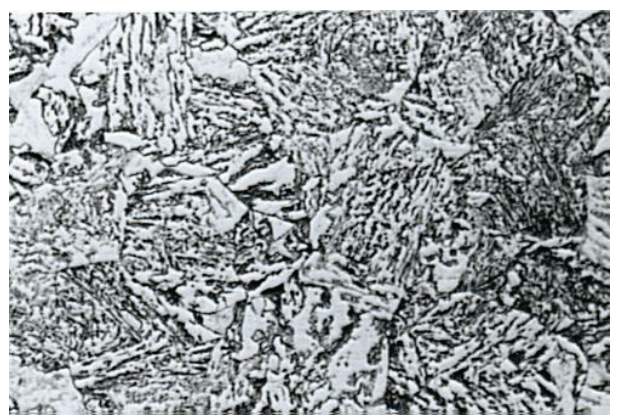

Figure 7 Microstructure of the hardened zone of tooth 1.

The precipitates of bainitic ferrite are closely related to the occurring decomposition temperature and with its drop, the orientation of the spines becomes slenderer. The presented structure may suggest too low an isothermal decomposition temperature. Fig. 8 shows microcracks on the tooth surface - specimen no. 1 . 
A plastic deformation of the top layer can be noticed on the edge. As the plastic deformation develops, slip band lines become visible. At the final stage, a shearing phenomenon occurs and, as its consequence, deformed zone delamination. A visible bainitic structure in the ferrite matrix.

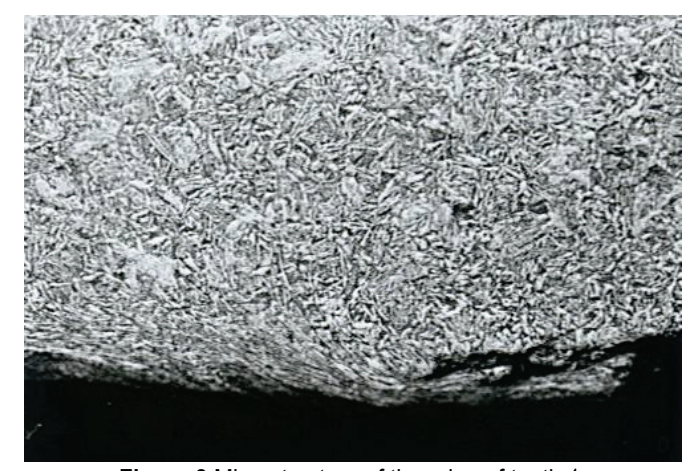

Figure 8 Microstructure of the edge of tooth 1.

\section{CONCLUSIONS}

From the analysis of the investigation results, two conclusions relating to the tooth failures can be drawn. One of the causes of tooth failures occurring can be either too large allowances removed during machining by grinding, or a non-uniform distribution of allowances during the grinding process itself. The second most probable cause can be too shallowly hardened a gear wheel top layer errors in the gear wheel induction hardening process. With the definitely softer gear wheel core, the shallowly hardened layer bends, as a result of which it delaminates. This brings to mind the conclusion that gear wheel failures arise either from a lack of adequate dimensional check-up prior to heat treatment, or inaccurate checks of hardened top layer thickness after heat treatment and after the finishing operation, that is grinding. The fact that deserves emphasizing is that the failure of the gear did not occur due to its excessive and improper operation.

\section{REFERENCES}

[1] Boral, P., Stoić, A., \& Kljajin, M. (2018). Machining of spur gears using a special milling cutter. Tehnicki vjesnik, 25(3), 701-705. https://doi.org/10.17559/TV-20171120121636

[2] Marković, K. \& Franulović, M. (2011). Contact stresses in gear teeth due to tip relief profile modification. Engineering Review, 3, 119-26.

[3] Marković, K. \& Vrcan, Ž. (2016). Influence of Tip Relief Profile Modification on Involute Spur Gear Stress. Transactions of FAMENA, 40, 59-70. https://doi.org/10.21278/TOF.40205

[4] Rackov, M., Milovančević M., Vereš, M., Banić, M., \& Miltenović, A. (2014). Optimization of HCR gearing geometry using generalized particle swarm optimization algorithm. Tehnicki vjesnik, 21(4), 723-732.

[5] Gołębski, R. (2012). Finite Element Method Model for Analysis of Contact Stress of Spur Gear. Mechanic, 7, 237242.

[6] Ochęduszko, K. (1972). Toothed gears, execution and assembly. Volume II, Warsaw: WNT.

[7] Skoć, A. \& Świtoński, E. (2016). Toothed gears. The principles of operation. Geometric and strength calculations. Warsaw: WNT.
[8] Michaelis, K., Hoehn, B., \& Oster, P. (2004). Influence of lubricant on gear failures - test methods and application to gearboxes in practice. Tribotest Journal, 11, 43-56. https://doi.org/10.1002/tt.3020110105

[9] Hoehn, B., Oster, P., \& Schedl, U. (1999). Pitting load capacity test on the FZG gear test rig with load-spectra and one-stage investigations. Tribotest Journal, 5, 417-430. https://doi.org/10.1002/tt.3020050407

[10] Aslantas, K. \& Tasgetiren, S. (2004). A study of Spur Gear Pitting Formation and Life Prediction. Wear, 257, 11671175. https://doi.org/10.1016/j.wear.2004.08.005

[11] Keer, L. \& Bryant, M. (1983). A Pitting Model for Rolling Contact Fatigue. Journal of Lubrication Technology, 105, 198-205. https://doi.org/10.1115/1.3254565

[12] Karpuschewski, B., Toefke, M., Beutner, M., \& Spintig, W. (2014). Surface Integrity Aspects of Milled Large Hardened Gears. Procedia CIRP, 13, 37-42. https://doi.org/10.1016/j.procir.2014.04.007

[13] Standard EN-ISO 1328-1:2015-01 Spur gears. The ISO system of tooth flank tolerances.

[14] Standard EN-ISO 14635-1:2015-10 Toothed gears. Testing procedures

[15] Kattelus, J., Miettinen, J., \& Lehtovaara, A. (2018). Detection of gear pitting failure progression with on-line particle monitoring. Tribology International, 118, 458-464. https://doi.org/10.1016/j.triboint.2017.02.045

[16] Ristivojević, M., Lazović, T., \& Vencl, A. (2013). Studying the load carrying capacity of spur gear tooth flanks. Mechanism and Machine Theory, 59, 125-137. https://doi.org/10.1016/j.mechmachtheory.2012.09.006

[17] Standard EN 10083-3:2007-01 Technical delivery conditions for alloy steels.

[18] Michalski, J. (2011). Hardening surface teeth gear for use in the mass production. Journal of the National Transport University of the Transport Academy of Ukraine, 193-200.

\section{Contact information:}

Rafał GOŁĘBSKI, Dr eng

Czestochowa University of Technology,

Institute of Mechanical Technologies,

Al. Armii Krajowej 21,

42-201 Czestochowa, Poland

E-mail: rafal@itm.pcz.pl

Arkadiusz SZAREK, Dr eng. Assoc. Prof.

Czestochowa University of Technology,

Institute of Mechanical Technologies,

Al. Armii Krajowej 21,

42-201 Czestochowa, Poland

E-mail: arek@iop.pcz.pl 